GRASAS Y ACEITES 72 (4)

October-December 2021, e427

ISSN-L: 0017-3495

https://doi.org/10.3989/gya.0663201

\title{
Computational studies on physico-chemical properties in the quality analysis of corn and peanut oil
}

\author{
๑S. Rubalya Valantina ${ }^{\mathrm{a}}$ and $\odot \mathrm{K}$. Arockia Jayalatha $\mathrm{a}^{\mathrm{b}, 凶}$ \\ ${ }^{a}$ Department of Physics, SASTRA Deemed University, Thanjavur - 613 401, India \\ ${ }^{\mathrm{b} S c h o o l ~ o f ~ E l e c t r i c a l ~ \& ~ E l e c t r o n i c s ~ E n g i n e e r i n g ~(S E E E), ~ S A S T R A ~ D e e m e d ~ U n i v e r s i t y, ~ T h a n j a v u r ~-~} 613$ 401, India \\ ${ }^{\square}$ Corresponding author: arockiajayalatha@eee.sastra.edu
}

Submitted: 06 June 2020; Accepted: 28 August 2020; Published online: 14 January 2022

\begin{abstract}
SUMMARY: Oils are commonly used in cooking as a frying medium which has been constantly subjected to different levels of heating. In this work, we have considered the most commonly used oils namely peanut oil and corn oil. Quality analyses of corn and peanut oils were made by relating macroscopic properties (ultrasonic velocity, viscosity, and density) to microscopic parameters (intermolecular free length, adiabatic compressibility etc.,) by subjecting them to six cycles of heating $\left(190^{\circ} \mathrm{C}\right)$. Variation in the mentioned property indexes, the degree of degradation and reusability for the next heating cycle that could be used in the food industry and processing were monitored. Using Newton-Laplace and Wood's equation, the adiabatic compressibility, acoustic impedance, and intermolecular free length of the oil were estimated from the experimental data. Ultrasonic velocity was observed linearly as related to viscosity with the dependency factor $\left(\mathrm{R}^{2}=0.932\right)$. With the aid of experiential data, the physical thermodynamic parameters, particularly particle size, packing factor, chemical potential, and L-J potential were computed. A high correlation factor was observed by fitting ultrasonic velocity, viscosity, and density to Parthasarathy and Bakshi, and Rodenbush equations. In the study, ultrasonic velocity, a macroscopic parameter, could be decoded to determine the microscopic variations in oil subjected to different temperatures in an industrial application.
\end{abstract}

KEYWORDS: Corn oil; LJ potential modeling; Peanut oil; Ultrasonic velocity; Viscosity

RESUMEN: Estudios computacionales de propiedades físico-químicas en análisis de calidad de aceites de maíz y maní. Los aceites se utilizan comúnmente en la cocina como un medio para freír y se someten de forma continua a diferentes niveles de calentamiento. En este trabajo, hemos considerado dos de los aceites comunmente utilizados, como los de maní y maíz. Los análisis de calidad de los aceites de maíz y maní se han realizado relacionando propiedades macroscópicas (velocidad ultrasónica, viscosidad y densidad) con parámetros microscópicos (longitud libre intermolecular, compresibilidad adiabática, etc.) sometiéndolo a seis ciclos de calentamiento $\left(190^{\circ} \mathrm{C}\right)$. La variación en las propiedades mencionadas indica el grado de degradación y su reutilización para el siguiente ciclo de calentamiento que podría ser lo usado en la industria y procesamiento de alimentos. Se utiliza la ecuación de Newton-Laplace y Wood, y a partir de los datos experimentales se estimaron la compresibilidad adiabática, la impedancia acústica y la longitud libre intermolecular de los aceites. La velocidad ultrasónica se observó estar linealmente relacionada con la viscosidad con el factor de dependencia $\left(\mathrm{R}^{2}=0,932\right)$. Con la ayuda de los datos experimentales, se calcularon los parámetros termodinámicos físicos como el tamaño de partícula, factor de empaquetamiento, potencial químico y potencial L-J. Se observó un factor de correlación alto ajustando la velocidad, viscosidad y densidad ultrasónicas a las ecuaciones de Parthasarathy y Bakshi y Rodenbush. En el estudio, la velocidad ultrasónica, un parámetro macroscópico, podría decodificarse para determinar las variaciones microscópicas en el aceite sometido a diferentes temperaturas en una solicitud industrial.

PALABRAS CLAVE: Aceite de cacahuete; Aceite de maiz; Modelado potencial de LJ; Velocidad ultrasónica; Viscosidad

Citation/Cómo citar este artículo: Rubalya Valantina S, Arockia Jayalatha K. 2021. Computational studies on physico-chemical properties in the quality analysis of corn and peanut oil. Grasas Aceites 72 (4), e427. https://doi.org/10.3989/gya.0663201

Copyright: (C2021 CSIC. This is an open-access article distributed under the terms of the Creative Commons Attribution 4.0 International (CC BY 4.0) License. 


\section{INTRODUCTION}

The ultrasonic technique is a non-destructive method used to estimate the quality of food products such as vegetables, milk, fruits, egg, fish, meat products, etc. An ultrasonic wave with a frequency greater than $1 \mathrm{MHz}$ is called a diagnostic wave which can interact with each particle of food items (Benedito et al., 2007). Hence the estimation of the composition of any food material can be done using ultrasonic waves. Low-intensity ultrasonic waves can be used to evaluate the quality, texture, and compositional changes in fats and oils (Benedito et al., 2002). Ultrasonic waves interact with short and long-chain fatty acids and can reveal the structure and degree of saturated fatty acids in the oil. Ultrasonic velocity through vegetable oil decreases with the increase in temperature and can be illustrated in three different regions (Benedito et al., 2002; Izbaim et al., 2010). A decrease in the ultrasonic velocity in region I (temperature range 0 to $22{ }^{\circ} \mathrm{C}$ ) exhibits a negative temperature coefficient due to the presence of the polymers monomer, dimer, trimer, and oligomer in the oil. When the molecular dimension of the polymer is high, it attenuates the ultrasonic wave which decreases its velocity. In region II (temperature range 24 to $37{ }^{\circ} \mathrm{C}$ approximately) a lowering of velocity is due to the slight melting of the above polymer. A decrease in the velocity in region III (temperature range 38 to $50{ }^{\circ} \mathrm{C}$ approximately) has been observed due to saturated bonds in fatty acids (McClements and Gunasekaran).

Frying is one of the most important cooking processes in the food industry. Oil is the sole base product in the preparation of fried foods. During the deep-frying process in snack industries, the oil undergoes heat and mass transfer when it is exposed to temperatures from $180{ }^{\circ} \mathrm{C}$ to its smoke point temperature, which in turn accelerates chemical reactions like oxidation, polymerization, hydrolysis, etc. (Katharina et al., 2012; Adolfo et al., 2006; Pushan et al., 2014). In general, fatty acids in the oil are made up of an even number of carbon atoms arranged in zig-zag fashion containing one or more carbon -to- carbon with one or more double bond, and a single carboxyl group (Reidoon, 2005). Oil is a mixture of a large number of fatty acids such as saturated fatty acids (SFA)- without any double bond; monounsaturated fatty acids (MUFA) - with a single double bond; and polyunsaturated fatty acids (PUFA) - with more than one double bond (Benedito et al., 2007; Benedito et al., 2002; Reidoon, 2005; Alireza and Abdolabbas, 2019). Karolina et al. (2020) investigated the quality of olive oil for cooking vegetables under domestic condition using its physical and chemical properties.

In the present study, fatty acid molecules were considered as a combination of hard spheres (atoms) to determine their chemical potential and particle size. The oil samples considered for the study were corn oil and peanut oil, which are highly used for frying. Corn oil has more than $85 \%$ un- saturated fatty acids and $13-14 \%$ saturated fatty acids (Reidoon, 2005). Peanut oil has $84.4 \%$ unsaturated fatty acids and $18-19 \%$ saturated fatty acids (David William, 2008; Fasino et al., 2006).

Dilapidation of oil has a negative effect on the aroma, color, texture, excellence, and safety of fried foodstuffs (Adolfo et al., 2006; Reidoon, 2005). In the evaluation of the quality of vegetable oil, researchers have developed analytical methods to estimate the degree of degradation of oil with heating cycles (Benedito et al., 2007; Adolfo et al., 2006, Reidoon, 2005). Though analytical analyses remain precise, they are quite laborious and costly. The consumption of degraded oil leads to atherosclerosis, coronary artery diseases, and increases LDL cholesterol, blood pressure, colon cancer, etc. (David, 2008; Fasino et al., 2006). Hence, in this study to analyze its quality, physical and chemical properties were used as an effective tool. The non-invasive ultrasonic method was used to characterize the oil by the interaction of the wave with a molecule in the oil that produces chemical changes (Benedito et al., 2007, Katharina et al., 2012). Viscosity is a conventional factor still used as an important index in the quality analysis of oil in some countries. The viscosity of oil varies with the contents in saturated and unsaturated fatty acids in the oil. Hence castoff as a quality index estimates the degradation level in oil (Fasina et al., 2006; Mohammad and Seyyed, 2020). The formation of free fatty acids and polar compounds due to chemical reactions upon heating decreases the reusability of oil.

In this study, corn and peanut oils exposed to six different cycles of heating to a frying temperature were taken as samples. Physical properties such as ultrasonic velocity, viscosity, density, acoustic impedance, adiabatic compressibility, and intermolecular free length were studied to determine the thermal degradation of the oils at every cycle of heating. Since oil is a dense and viscous liquid made up of short and long-chain fatty acids to take it as freely sliding molecules, hard-sphere models such as Percus-Yevick (PY), Scaled Particle Theory (SPT) and Mansoori, Carnahan, Starling, and Leland (MCSL) model were adopted in the determination of chemical potential, interaction potential, particle size and the packing factor of atoms in fatty acids in oil (Everett, 1963). These parameters were estimated with experimentally determined ultrasound velocity as the main input. The study related the distribution of molecules in oil to degradation and also to the forces existing between molecules in corn oil and peanut oil.

\section{MATERIALS AND METHODS}

\subsection{Sample Preparation}

The branded samples of corn (Zea mays) and peanut (Arachis hypogaea) oil needed for the study were bought from a supermarket in Thanjavur. They were separated as 
unheated and heated $\left(190{ }^{\circ} \mathrm{C}\right)$ samples at different cycles and stored at ambient temperature. Heated samples were prepared by repeated heating cycles in a copper beaker surrounded with an oil bath to $190{ }^{\circ} \mathrm{C}$ six times (Rubalya et al., 2016). Each unheated sample was stored as a set of three $100 \mathrm{ml}$ samples (Total of 42 samples) in dark bottles.

\subsection{Experimental Measurement}

\subsubsection{Ultrasonic Measurement}

A of velocity measurement was taken for all 42 samples by taking $20 \mathrm{ml}$ of the sample in the liquid column of Ultrasonic interferometer (F-80, Mittal Enterprises, Delhi, India) (Rubalya et al., 2013). The device was provided with an electric signal connected to a flat plate mounted on a piezo-electric crystal with capacitive reactance that produces $2 \mathrm{MHz}$ frequency. The parameters associated with ultrasonic velocity (U), (i) Acoustic impedance (Z) relate the velocity of sound and density of the medium as given by the equation:

$$
Z=\rho U \mathrm{~kg} / \mathrm{m}^{2} \mathrm{~s}
$$

(ii) Newton- Laplace equation links the elastic bulk modulus (K) of liquid with velocity and density of oil by:

$$
K=\rho U^{2} \mathrm{~N} / \mathrm{m}^{2}
$$

(iii) Wood's equation gives the relation between adiabatic compressibility with velocity and density of sound in liquid:

$$
\beta=\frac{1}{\rho U^{2}} \mathrm{~m}^{2} / \mathrm{N}
$$

(iv) Molecular free length $\mathrm{L}_{\mathrm{f}}$, it is the distance covered by the propagating acoustic waves between the surfaces of two neighboring molecules in a liquid. Intermolecular free length is the ratio of available volume to the surface area of the molecule. Jacobson (1953) and Pandey et al. (1979) have shown an empirical relation between ultrasonic velocity $U$, the density $\rho$ and the intermolecular free length $\mathrm{L}_{\mathrm{f}}$ of a liquid as:

$$
\begin{aligned}
& L_{f} U \rho^{1 / 2}=K \\
& \text { and } L_{f}^{2}=K^{2} \beta \quad N^{-1} m^{2} \\
& \text { where } L_{f}=K \sqrt{ } \beta \text { i.e. } L_{f}=K \sqrt{ } 1 /\left(U^{2} \rho\right)
\end{aligned}
$$

where, $\mathrm{K}$ is Jacobson constant at room temperatures and $\beta$ is the adiabatic compressibility of liquid.

\subsubsection{Density Measurement}

The density measurement of density was determined using Pycnometer, following the ASTM standard method D891-09 (Rubalya et al., 2016).

\subsubsection{Viscosity Measurement}

The kinematic viscosity $(\eta)$ of the oil was measured using a Redwood viscometer (Associated Instrument Manufacturers India Private Limited, New Delhi, India) (Rubalya et al., 2016).

\subsection{Statistical analysis}

All data pertaining to viscosity, density, and ultrasonic velocity were recorded as mean $\pm \mathrm{SD}$ and analyzed using SPSS (version 15). One-way analysis of variance was performed by ANOVA procedures. Significant differences among the parameters were determined by Duncan's multiple range tests. Time of heating was taken as an independent parameter; whereas viscosity, density, and ultrasonic velocity were dependent parameters. Significance and variances (p) are illustrated in the footnotes of Tables 1 and 2 .

\subsection{Theory}

\subsubsection{Study of Empirical equations}

The packing fractions of molecules in corn and peanut oil were analyzed using PY, SPT, and MCSL models (Heying and Corti, 2004; Lebowitz, 1964; Mandell and Reiss, 1975; Mansoori et al., 1971). The analyses were carried out by employing the experimentally measured ultrasound velocity as they are directly related to the thermodynamic behaviour of the system. The PY model proposes an equation of state for hard-sphere fluids, which was analyzed in terms of the viral co-efficient (Mandell and Reiss, 1975). The PY equation mainly involves the radial distribution function of a fluid, which can be generalized to an m-component mixture (Lebowitz, 1964; Percus and Yevick, 1958). SPT explains the feasibility of cavity formation in hard-sphere mixture fluids (Mansoori et al., 1971; Reiss et al., 1959). In addition, the glycerol in the oil leaves a space for the fatty acids to occupy and forms a cavity. A system under study is an m-component mixture and this is possible only because the probability of cavity formation is large (Percus and Yevick, 1958; Reiss et al., 1959; Ravi et al., 2008). An equation relating ultrasonic velocity (U) with the change in the molecular weight using the MCSL model incorporating particle interaction in the PY equation is given as (Wertheim, 1963; Yarnell et al., 1973): 


$$
U=X^{-1} \sqrt{\frac{R T}{\gamma M}}
$$

where, R-gas constant, T- temperature, $\gamma$ - specific heat ratio, $\mathrm{M}-$ molecular weight, $\mathrm{X}^{-1}$ is the expression that depends on three different theories that define the state of the system (Wertheim, 1963; Yarnell et al., 1973; Yu et al., 2002). The three theories that define these systems are the Percus-Yevick (PY) approach, Scaled Particle Theory (SPT) and Mansoori Carnahan Starling Leland (MCSL) model (Wertheim, 1963; Yu et al., 2002). Based on these models, the equation for $\mathrm{X}$ takes the form:

$$
\begin{gathered}
X_{P Y}^{-1}=\frac{1+2 y}{(1-y)^{2}} \\
X_{S P T}^{-1}=\frac{(1+2 y)^{2}}{(1-y)^{3}} \\
X_{M C S L}^{-1}=\frac{y^{4}-4 y^{3}+4 y^{2}+4 y+1}{(1-y)^{4}}
\end{gathered}
$$

Using equations 6, 7 and 8 packing fraction and hence particle diameter (y) were deduced using an expression with $\rho_{n}$ which is the number density of the uniform fluid and $\sigma$ the particle size:

$$
y=\frac{\pi}{\rho_{n}} \sigma^{3}
$$

\subsubsection{Estimation of chemical potential $(\mu / k T)$}

Chemical potential is the energy that can be emitted or absorbed when a particle is added to a system. It is also known as partial molar free energy. In heterogeneous systems, it is the change in internal energy of the system when new particles are added or when the condition of the system is altered like the variation in temperature. The density of a uniform hard-sphere fluid is related to its chemical potential through the Carnahan - Starling equation of state and is given in equation 1, respectively (Wertheim, 1963; Yarnell et al., 1973; Yu et al., 2002; Lennard, 1924):

$$
\left[\frac{\mu}{k T}\right]=\ln \left(\rho_{n}\right)+\left\{y\left(\frac{8+9 y+3 y^{2}}{(1-y)^{2}}\right)\right\}
$$

where, $\rho_{n}$ is the number density of the uniform fluid.

\subsubsection{Estimation of Lennard - Jones potential (LJ Potential)}

The Lennard - Jones potential (5- 8 equations) defines the interaction between a pair of neutral atoms or molecules. The potential description includes i) repulsive term $\mathrm{r}^{-12}$ and ii) long-range attractive term $\mathrm{r}^{-6}$ and the potential is defined as (Yarnell et al., 1973; Lennard, 1924):

$$
V_{L J}(r)=\frac{4 \varepsilon}{k}\left[\left(\frac{\sigma}{r}\right)^{12}-\left(\frac{\sigma}{r}\right)^{6}\right]
$$

where, $\varepsilon / \mathrm{k}$ defines inter particle- potential and can be estimated using the following equation (Lennard, 1924):

$$
\frac{\varepsilon}{k}=\frac{2 T}{n_{s}}\left[-\frac{\mu}{k T}+\mu_{o}-3 \ln \Delta\right]
$$

where, $\mathrm{n}_{\mathrm{s}}$ - number of nearest neighboring atoms.

\section{RESULTS AND DISCUSSION}

\subsection{Variation in physical property of oil}

Tables 1 and 2 show the variations in viscosity, density, ultrasonic velocity and ultrasonic parameters such as velocity, acoustic impedance and intermolecular free length of corn and peanut oil exposed to different heating times.

\subsubsection{Ultrasonic velocity}

Ultrasound velocity $(\mathrm{U})$ is subjected to intermolecular interfaces and molecular connotations, which enhance the significance of ultrasound velocity measurements for the molecular state, structure, composition and various processes (Izbaim et al., 2010). From the Tables 1 and 2, it can be observed that ultrasonic velocity decreases with cycles of heating and is due to less transmission of ultrasonic wave and scattering produced by molecular clusters in the oil (Rubalya et al., 2013).

Figures 1 (a), (b) and (c) illustrate the disparity in ultrasonic velocity, adiabatic compressibility, and viscosity with heating time, which is observed to be greater in peanut oil compared to corn oil. The formation of polymers and saturated fatty acids due to hydrogenation, oxidation, and hydrolysis accelerate the clustering of molecules that increase density and viscosity in the oil, and in turn, reduce the ultrasonic velocity (Benedito et al., 2007; Rubalya et al., 2013; Izbaim et al., 2010). The reduction in ultrasonic velocity reflects a decrease in intermolecular free length due to the conversion of a double bond in fatty acids to a single bond by the addition of a hydrogen atom that forms saturated fatty acids by which the packing density of molecule increases (Rubalya et al., 2017). 
TABLE 1. Variations in parameters $(\rho),(\eta),(U),(Z),(L)$ and $(\beta)$ of corn oil upon heating

\begin{tabular}{|c|c|c|c|c|c|c|}
\hline $\begin{array}{l}\text { Time of heating } \\
\text { in } h\end{array}$ & $\begin{array}{l}\text { Density ( } \rho) \\
10^{3} \mathrm{~kg} / \mathrm{m}^{3}\end{array}$ & $\begin{array}{c}\text { Viscosity ( } \eta) \\
10^{-6} \mathrm{~m}^{2} / \mathrm{s}\end{array}$ & $\begin{array}{l}\text { Ultrasonic } \\
\text { velocity } \\
\text { (U) } 10^{3} \mathrm{~m} / \mathrm{s}\end{array}$ & $\begin{array}{c}\text { Acoustic } \\
\text { impedance }(Z) \\
10^{6} \mathrm{~kg} / \mathrm{m}^{2} \mathrm{~s}\end{array}$ & $\begin{array}{c}\text { Intermolecular } \\
\text { free length }(L) \\
\qquad 10^{-10} \mathrm{~m}\end{array}$ & $\begin{array}{c}\text { Adiabatic Com- } \\
\text { pressibility ( }(\beta) \\
10^{-10} \mathrm{~N}^{-1} \mathrm{~m}^{2}\end{array}$ \\
\hline 0 & $0.904 \pm 0.008^{\mathrm{a}}$ & $61.74 \pm 0.15^{\mathrm{b}}$ & $1.48 \pm 0.035^{\mathrm{a}}$ & 1.539 & 0.329 & 4.390 \\
\hline 0.5 & $0.909 \pm 0.005^{\mathrm{a}}$ & $76.41 \pm 0.23^{\mathrm{b}}$ & $1.45 \pm 0.028^{\mathrm{a}}$ & 1.581 & 0.338 & 4.364 \\
\hline 1 & $0.911 \pm 0.012^{\mathrm{a}}$ & $89.22 \pm 0.14^{\mathrm{a}}$ & $1.44 \pm 0.019^{\mathrm{a}}$ & 1.598 & 0.342 & 4.345 \\
\hline 1.5 & $0.919 \pm 0.003^{\mathrm{a}}$ & $93.90 \pm 0.27^{\mathrm{a}}$ & $1.41 \pm 0.027^{b}$ & 1.678 & 0.359 & 4.227 \\
\hline 2 & $0.923 \pm 0.017^{\mathrm{a}}$ & $109.51 \pm 0.13^{\mathrm{a}}$ & $1.38 \pm 0.030^{\mathrm{b}}$ & 1.697 & 0.363 & 4.269 \\
\hline 3 & $0.926 \pm 0.015^{\mathrm{a}}$ & $112.42 \pm 0.08^{\mathrm{a}}$ & $1.35 \pm 0.023^{\mathrm{b}}$ & 1.701 & 0.364 & 4.355 \\
\hline 5 & $0.928 \pm 0.011^{\mathrm{b}}$ & $118.33 \pm 0.04^{\mathrm{a}}$ & $1.31 \pm 0.029^{\mathrm{a}}$ & 1.677 & 0.360 & 4.553 \\
\hline
\end{tabular}

One-way ANOVA analysis was determined $(\mathrm{n}=3$ ) by Duncan's multiple range tests. a $\mathrm{p}$-value $<0.001$ and $\mathrm{b}$-value $<0.05$ are significant.

TABLE 2. Variations in parameters $(\rho),(\eta),(U),(Z),(L)$ and $(\beta)$ of peanut oil upon heating

\begin{tabular}{|c|c|c|c|c|c|c|}
\hline $\begin{array}{c}\text { Time of } \\
\text { heating in } h\end{array}$ & $\begin{array}{c}\text { Density }(\rho) 103 \\
\mathrm{~kg} / \mathrm{m}^{3}\end{array}$ & $\begin{array}{c}\text { Viscosity }(\eta) \\
10^{-6} \mathbf{m}^{2} / \mathbf{s}\end{array}$ & $\begin{array}{c}\text { Ultrasonic } \\
\text { velocity }(\mathrm{U}) 10^{3} \\
\mathrm{~m} / \mathrm{s}\end{array}$ & $\begin{array}{c}\text { Acoustic } \\
\text { impedance (Z) } \\
10^{6} \mathrm{~kg} / \mathrm{m}^{2} \mathrm{~s}\end{array}$ & $\begin{array}{l}\text { Intermolecular } \\
\text { free length }(\mathrm{L}) \\
\quad \times 10^{-10} \mathrm{~m}\end{array}$ & $\begin{array}{c}\text { Adiabatic } \\
\text { Compressibility } \\
\text { (ק) } \mathbf{1 0}^{-10} \mathrm{~N}^{-1} \mathrm{~m}^{2}\end{array}$ \\
\hline 0 & $0.932 \pm 0.044^{\mathrm{b}}$ & $68.51 \pm 0.06^{\mathrm{b}}$ & $1.46 \pm 0.039^{c}$ & 1.415 & 0.303 & 4.853 \\
\hline 0.5 & $0.944 \pm 0.072^{\mathrm{a}}$ & $76.12 \pm 0.53^{\mathrm{c}}$ & $1.44 \pm 0.046^{\mathrm{b}}$ & 1.405 & 0.301 & 4.929 \\
\hline 1 & $0.949 \pm 0.065^{\mathrm{a}}$ & $105.39 \pm 0.28^{\mathrm{a}}$ & $1.43 \pm 0.012^{\mathrm{b}}$ & 1.396 & 0.299 & 5.002 \\
\hline 1.5 & $0.956 \pm 0.029^{b}$ & $132.26 \pm 0.17^{\mathrm{a}}$ & $1.41 \pm 0.080^{\mathrm{a}}$ & 1.415 & 0.303 & 5.019 \\
\hline 2 & $0.967 \pm 0.087^{\mathrm{c}}$ & $151.24 \pm 0.42^{\mathrm{c}}$ & $1.32 \pm 0.028^{\mathrm{b}}$ & 1.449 & 0.310 & 5.227 \\
\hline 3 & $0.971 \pm 0.024^{\mathrm{b}}$ & $176.73 \pm 0.61^{\mathrm{c}}$ & $1.19 \pm 0.035^{\mathrm{b}}$ & 1.354 & 0.290 & 6.205 \\
\hline 5 & $0.983 \pm 0.031^{\mathrm{b}}$ & $183.45 \pm 0.34^{\mathrm{b}}$ & $0.94 \pm 0.004^{\mathrm{c}}$ & 1.085 & 0.232 & 9.807 \\
\hline
\end{tabular}

One-way ANOVA analysis was determined $\left(\mathrm{n}=3\right.$ ) by Duncan's multiple range tests. ${ }^{\mathrm{a}} \mathrm{p}$-value $<0.001,{ }^{\mathrm{b}} \mathrm{p}$-value $<0.05$, and ${ }^{\mathrm{c}} \mathrm{p}$-value $<$ 0.005 are significant.

Adiabatic compressibility, Bulk modulus, and molecular free length determine the arrangement of atoms and molecules that influence the inter-atomic forces like London dispersion force, and Van der Waals force, which are seen between molecules in liquid systems (Izbaim et al., 2010; Rubalya et al., 2017; Sankarappa et al., 2005). The nature of forces and their strength between molecules can be understood by determining their internal pressure (Lei et al., 2016). Figure 1 (b) shows an increase in adiabatic compressibility with heating time for peanut oil. However, it remains almost constant for corn oil as the specific molecular interaction between molecules is almost the same.

Tables 1 and 2 elucidate the variation in acoustic impedance with heating time for peanut and corn oil. Acoustic impedance $(Z)$ resists the flow of the ultrasonic wave through the liquid. When bonding between atoms becomes strong, the density of the oil sample will increase with the proliferation in packing density. Unsaturated fatty acids like oleic and linoleic acids get saturated to palmitic and stearic SFA that reduces the flow of sound in oil (Benedito et al., 2007; Benedito et al., 2002). Corn oil shows an experiential rise of $Z$ up to $10.5 \%$ after six cycles of heating but in peanut oil, it varies by $33.45 \%$. The $\mathrm{Z}$ value of peanut is found to be greater, as the density of the oil increases due to an increase in SFA formed by degradation. Jose Benedito (2007) studied the quality of fried oils using the ultrasonic parameter and correlated it with polar and polymer compounds that are formed by the degradation in oil. Lei Zang et al. (2016) have stated that oil exposed to an ultrasonic oscillatory wave produce cavitation bubbles as it passes through the sample, inducing pressure variation. This interaction of the ultrasonic wave with the oil and the breaking of cavitation bubbles will induce the oxidation effect and accelerate thermal degradation. Hence, from the measured ultrasonic velocity, the quality of oil and its further usage can be evaluated.

\subsubsection{Viscosity}

Variation in viscosity with respect to heating time for corn and peanut oils is shown in Figure 1 (c). The viscosity 

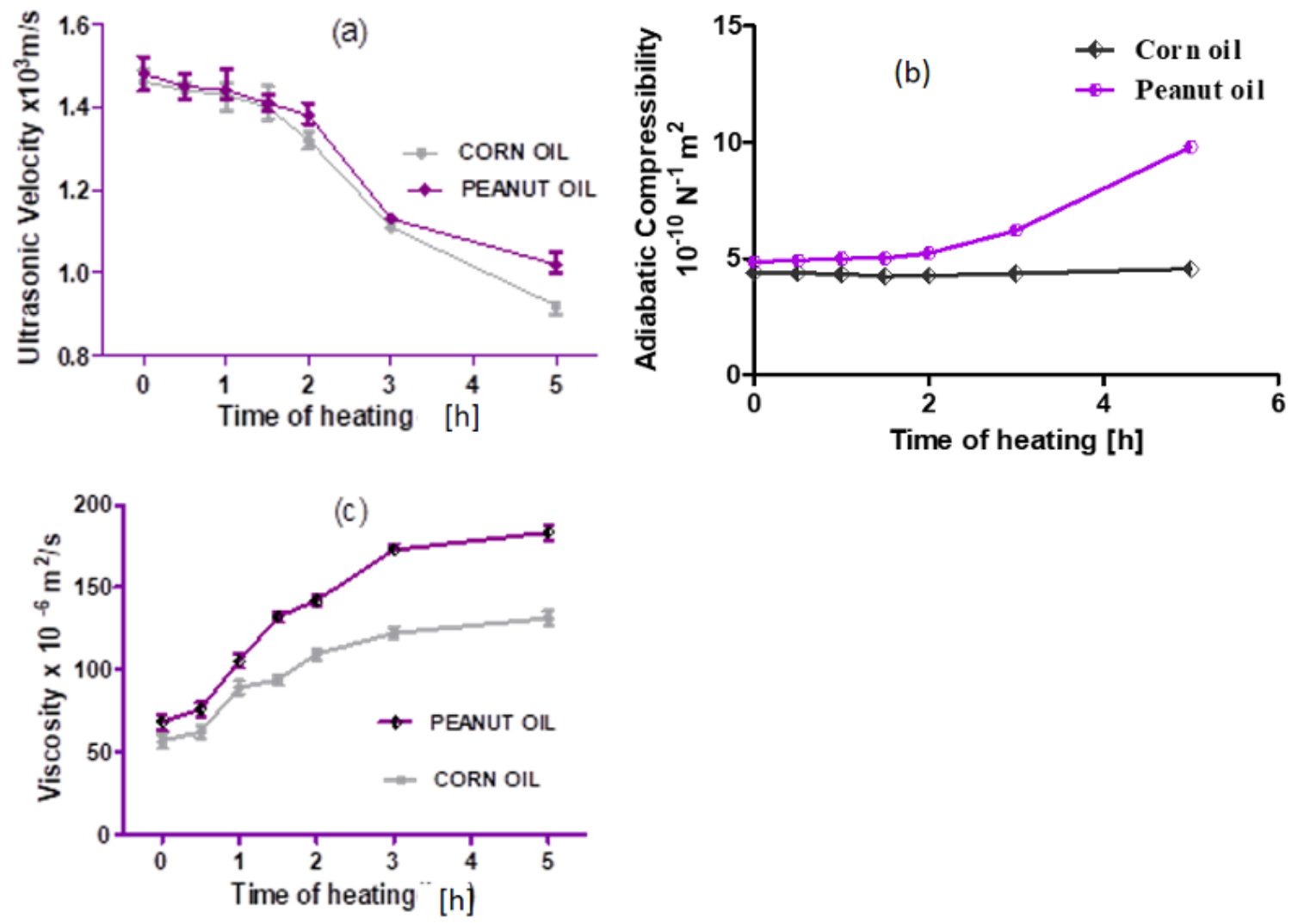

FIGURE 1. Variation of (a) Ultrasonic velocity for three trials ( $n=3$ ) (b) Adiabatic compressibility (for $n=1$ ) (c) Viscosity for three trials $(n=3)$ of peanut and corn oil with time of heating. The observed experimental deviation has been marked in (a) and (c).

of the oil is less when it is composed of a large amount of unsaturated fatty acids and becomes high with an increase in long-chain saturated fatty acids (Adolfo et al., 2006; Fasina et al., 2006; Rubalya et al., 2016). Thus, the viscosity of oil increases with an increase in heating cycles as the quantity of SFA becomes greater. This variation in kinematic viscosity exhibits a steeper increase in peanut oil compared to corn oil, which is due to the molecular structural change in composition and decrease in the degree of unsaturated fatty acids (David, 2008; Everett, 1963). Viscosity ranges from 56.7 to $131.3 \times 10^{-6} \mathrm{~m}^{2} / \mathrm{s}$ for corn oil; whereas it varies for peanut oil from 68.51 to $183.5 \times 10^{-6}$ $\mathrm{m}^{2} / \mathrm{s}$ in six cycles of heating. Viscosity increases by $47.6 \%$ in corn oil after five hours of heating and is observed to be nearer to twice the times of its unheated value. This is due to the increase in altered double bonds to a single bond in fatty acids. The reason for variation in viscosity is due to the existence of long-chain saturated fatty acids (Rubalya et al., 2016, Rubalya et al., 2017). Similarly, from the rheological study, peanut oil shows a viscosity value $62.7 \%$ greater than the first time of heating. This is due to the increase in saturated bonds formed by the degradation of oil and also to the presence of arachidic and behenic acid with C22 long-chain saturated fatty acids (Reidoon, 2005).

\subsection{Correlation between ultrasonic velocity and viscosity}

Figure 2 exemplifies the correlation of ultrasonic velocity with viscosity and dependency factor $\mathrm{R}^{2}=0.932$. A scattered graph is drawn between the two parameters and the trend line shows a decrease in velocity with an in-

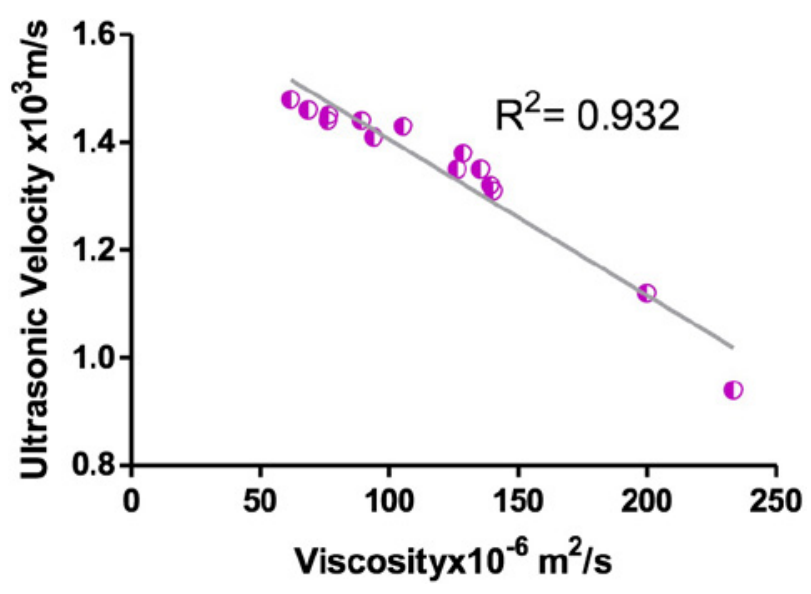

FIGURE 2. Correlation between average data $(n=1)$ of viscosity and ultrasonic velocity of peanut and corn oil. 
crease in viscosity due to the formation of large amounts of polymers, and polar compounds which increase molecular clustering (Benedito et al., 2007; Benedito et al., 2002; Rubalya et al., 2016). It can be inferred from the Figure 2 that ultrasonic velocity and viscosity are negatively correlated because of an increase in chain length of triglycerides, saturated fatty acids and the molecular weight of chemical species. Variation in ultrasonic velocity with viscosity has been correlated for both peanut and corn oil samples and the corresponding equation is given in eq. 13 , respectively:

$$
\text { Ultrasonic velocity }=-0.0023(\text { viscosity })+1.65
$$

\subsubsection{Density}

Tables 1 and 2 show that the density of corn oil and peanut oil increases with heating cycles. After 6 cycles of heating, it is observed that the density of corn oil increases by $10.9 \%$ whereas in peanut oil it increases by $18 \%$. The experimental density of oil was calculated after each cycle of heating at room temperature. The density of oils greatly depends on the molecular weight of its chemical compounds. In general, the molecular weight of oil rises due to the formation of mono, di and triglyceride oligomers and also with an increase in saturated fatty acids. From the measured physical properties, it is pragmatic that changes in molecular structure in the composition of oil influence the changes in the physical property.

Ultrasonic velocity (U) with a viscosity $(\eta)$ and density $(\rho)$ are related to the empirical equation given by:

$$
\frac{(U)^{1 / 3}}{\rho}=A+\frac{B}{\sqrt{\eta}}
$$

The values are fitted to the above equation and the dependency factor $\left(\mathrm{R}^{2}\right)$ was experiential between 0.922 and 0.966. Constants $\mathrm{A}=-0.387$ and $\mathrm{B}=0.403$ are correlation coefficients in linear fitting of the above equation (15). The variations are due to the change in the molecular weight of unsaturated fatty acids and other unsaturated chemical composites in oil even after repeated cycles of frying. The oil contains $90 \%$ of short and long-chain fatty acids and triglycerides that increase the number of molecules per unit volume, which highly influences the density and viscosity of the oil. Rodenbush et al. (1999) had related density and viscosity of oil as both factors are temperature-dependent by the equation:

$$
\rho=D+\frac{E}{\sqrt{\eta}}
$$

Density and viscosity are important quality analysis indices in the oil industry for the pumping, pipelining, designing of the processing system, etc. If the density is known the viscosity of the oil can be determined using equation (15). The dependency of density with viscosity using the Rodenbush equation varies from 0.902 to 913 and was computed using least square fitting, where D $=1.308$ and $\mathrm{E}=-1.302$ are the correlation coefficients. The variation in accuracy is due to the heavy molecules polymer: monomer, dimer, and triacylglycerol, which are formed upon heating the oil at the frying temperature in different time cycles.

\subsection{Hard sphere model for liquid system}

The density of oil increases with heating time and so the packing density of oil also increases. The estimated values for the packing fraction of corn and peanut oil samples at different heating conditions are illustrated in Tables 3 and 4 using the four different models. The packing fraction determined by the PY model is very high compared to the SPT and MCSL models. The investigation illustrates that the number of atoms in a given volume increases with heating time and the system becomes dense by increasing the duration of heating because of this high packing fraction.

To compute PY, SPT and MCSL hard-sphere models, the molecular weight of the fatty acids in oil was determined by Tadao (1985). In his study, a linear variation between the molecular weight and viscosity was estimated for the oil and modified oil. He also observed that the molecular weight of th base oil was disseminated in a narrow range; whereas for blended oil there was a wide range of distribution. When the oil was heated to a smoke point temperature, it underwent chemical breakdown and this complicated behavior of molecules in the oil was explained using the Marangoni effect (Tadao, 1985). The related molecular weight $(\mathrm{M})$ of oil with kinematic viscosity in a heat transfer analysis was estimated by taking the measured viscosity and relative approximate molecular weight variations between up to $588 \mathrm{~g} / \mathrm{mol}$ of monomer, dimer and trimer forms of fatty acids using the linear fitting relation (Tadao, 1985).

\subsubsection{Packing fraction}

The backscattering of the ultrasonic wave per unit volume by the ensemble of the molecule in a plane can be theoretically estimated using the PY model (Percus and Yevick, 1958; Wertheim, 1963). The packing fraction of molecules in oil upon degradation with irregular shape in a given volume can be predicted using the PY model. Tables 3 and 4 exemplify that up to sample S4 the packing fraction increases and decreases slightly to $0.002 \%$ towards S7 due to the spatially random distribution of molecules in a given volume of oil. The estimated packing fraction by the SPT model envisages the compressi- 
TABLE 3. Oil System: Computed chemical parameters of Corn oil heated to $190{ }^{\circ} \mathrm{C}$ by considering the average of ultrasound velocity ( $\mathrm{n}=1$ )

\begin{tabular}{|c|c|c|c|c|}
\hline \multicolumn{5}{|c|}{ Model: PY (Percus-Yevick) } \\
\hline Time of heating (h) & Packing fraction $(\mathrm{y})$ & Particle Size $(r)[\mu \mathrm{m}]$ & Chemical Potential & Inter-particle potential \\
\hline 0 & 0.9329 & 0.1137 & 6,888 & $-13,050$ \\
\hline 0.5 & 0.9331 & 0.1157 & 6,948 & $-13,088$ \\
\hline 1 & 0.9341 & 0.1187 & 7,264 & $-13,280$ \\
\hline 1.5 & 0.9337 & 0.1188 & 7,126 & $-13,196$ \\
\hline 2 & 0.9333 & 0.1197 & 7,016 & $-13,129$ \\
\hline 3 & 0.9331 & 0.1208 & 6,936 & 13,080 \\
\hline 5 & 0.9323 & 0.1214 & 6,712 & $-12,940$ \\
\hline \multicolumn{5}{|c|}{ Model: SPT (Scaled Particle Theory) } \\
\hline 0 & 0.7822 & 0.1072 & 260.2 & $-5,135$ \\
\hline 0.5 & 0.7826 & 0.1091 & 261.3 & $-5,137$ \\
\hline 1 & 0.7846 & 0.1121 & 267.09 & $-5,153$ \\
\hline 1.5 & 0.7837 & 0.1121 & 264.4 & $-5,145$ \\
\hline 2 & 0.7831 & 0.1129 & 262.5 & $-5,139$ \\
\hline 3 & 0.7825 & 0.1140 & 260.94 & $-5,134$ \\
\hline 5 & 0.7810 & 0.1144 & 256.70 & $-5,121$ \\
\hline \multicolumn{5}{|c|}{ Model: MCSL (Mansoori Carnahan Starling Leland) } \\
\hline 0 & 0.7074 & 0.1037 & 137.06 & $-4,973$ \\
\hline 0.5 & 0.7078 & 0.1055 & 137.37 & $-4,969$ \\
\hline 1 & 0.7099 & 0.1084 & 139.22 & $-4,960$ \\
\hline 1.5 & 0.70895 & 0.1084 & 138.34 & $-4,963$ \\
\hline 2 & 0.7083 & 0.1092 & 137.72 & $-4,964$ \\
\hline 3 & 0.70773 & 0.1102 & 137.18 & $-4,964$ \\
\hline 5 & 0.70618 & 0.1107 & 135.78 & $-4,969$ \\
\hline
\end{tabular}

bility of hard-sphere in an oil sample which is of medium density. This confirms the cavity formation. As the major constituents of oils are fatty acids, they combine to form a system if their potentials coincide. Tables 3 and 4 illustrate the packing fraction increase with an increase in the duration of heating to up to 1.5 hours. As heating cycles are increased, unsaturated fatty acids in 'cis' form are converted to 'trans' form of saturated fatty acids (Pushan et al., 2009; Reidoon, 2005; David, 2008; Fasina et al., 2006). Because of this number of particles within the reference area and its size, its packing fraction in a given volume is greater. When heating cycles are increased the heavy molecules may disintegrate to form molecules of lower dimension. Using the MCSL model the bulk phase behavior in a complex liquid like oil under pressure variation of the propagation of the ultrasonic wave will exhibit the density functional theory. The packing fraction of atoms/molecules that are calculated using the models increases till 90 minutes of heating time and then decreases by $0.005 \%$ at 5 hours of heating. In this bulk medium liquid the calculated packing fraction varies in the order PY $>$ SPT $>$ MCSL. By comparing the corn and peanut oil using three models, it has been observed that peanut oil has greater packing fraction.

\subsubsection{Particle size}

Figure 3 shows the variation in particle diameter/size of hard-sphere with heating time by comparing the behavior of corn and peanut oil. The calculated particle size of peanut oil is greater than corn oil using all three models (PY, SPT, MCSL) due to the presence of a large amount of long-chain saturated fatty acids. These hard-sphere models exemplify the microscopic description of the distribution of molecules in a given volume according to its dimension. The particle size using the PY model for peanut oil starts increasing by $0.008 \%$ for 0.5 hours heated sample and $0.001 \%$ for 5 hours compared to corn oil in a micrometer range. Using the SPT model, a systematic analytical method, the particle size varies from $0.02 \%$ to $0.09 \%$ from 1.5 to 5 hours of heating. The changes in the particle size using the fundamental measure theory MCSL model are very significant compared to the other two models.

\subsubsection{Chemical potential (CP)}

In colloidal science and liquid state theory, the three models (PY, SPT, MCSL) are very important in the study of the distribution of heavy and low weight molecules that are formed when exposed to different temperatures (Reiss 
Computational studies on physico-chemical properties in the quality analysis of corn and peanut oil $\bullet$

TABLE 4. Oil System: Computed chemical parameters of Peanut oil heated to $190{ }^{\circ} \mathrm{C}$ by considering the average of ultrasound velocity ( $\mathrm{n}=1$ )

\begin{tabular}{|c|c|c|c|c|}
\hline \multicolumn{5}{|c|}{ Model: PY (Percus-Yevick) } \\
\hline Time of heating (h) & Packing fraction $(\mathrm{y})$ & Particle Size $(r)[\mu \mathrm{m}]$ & Chemical Potential & Inter-particle potential \\
\hline 0 & 0.93265 & 0.1137 & 6,813 & $-13,003$ \\
\hline 0.5 & 0.93280 & 0.1151 & 6,857 & $-13,031$ \\
\hline 1 & 0.93442 & 0.1196 & 7,369 & $-13,342$ \\
\hline 1.5 & 0.93447 & 0.1209 & 7,385 & $-13,352$ \\
\hline 2 & 0.93286 & 0.1221 & 6,875 & $-13,042$ \\
\hline 3 & 0.92979 & 0.1230 & 6,027 & $-12,492$ \\
\hline 5 & 0.9215 & 0.1232 & 4,342 & $-11,226$ \\
\hline \multicolumn{5}{|c|}{ Model: SPT (Scaled Particle Theory) } \\
\hline 0 & 0.78172 & 0.1072 & 258.84 & $-5,131$ \\
\hline 0.5 & 0.7820 & 0.1086 & 259.60 & $-5,134$ \\
\hline 1 & 0.78524 & 0.1129 & 268.99 & $-5,159$ \\
\hline 1.5 & 0.78534 & 0.1141 & 269.264 & $-5,159$ \\
\hline 2 & 0.78211 & 0.1152 & 259.73 & $-5,129$ \\
\hline 3 & 0.77607 & 0.1158 & 243.36 & $-5,081$ \\
\hline 5 & 0.7603 & 0.1155 & 207.91 & $-4,988$ \\
\hline \multicolumn{5}{|c|}{ Model: MCSL (Mansoori Carnahan Starling Leland) } \\
\hline 0 & 0.70689 & 0.1037 & 136.61 & $-4,975$ \\
\hline 0.5 & 0.70719 & 0.1050 & 136.84 & $-4,972$ \\
\hline 1 & 0.71055 & 0.1092 & 139.80 & $-4,958$ \\
\hline 1.5 & 0.71067 & 0.1104 & 139.88 & $-4,956$ \\
\hline 2 & 0.70730 & 0.1114 & 136.76 & $-4,964$ \\
\hline 3 & 0.70104 & 0.1119 & 131.35 & $-4,984$ \\
\hline 5 & 0.69485 & 0.1116 & 119.25 & $-5,059$ \\
\hline
\end{tabular}

(a) PY Model

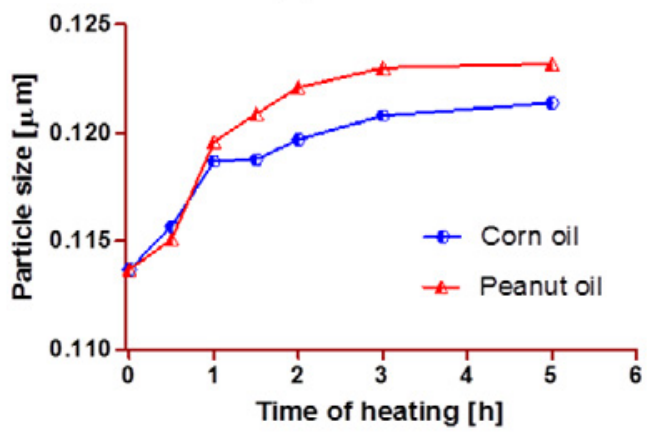

(b) SPT ModeI



(c) MCSL Model

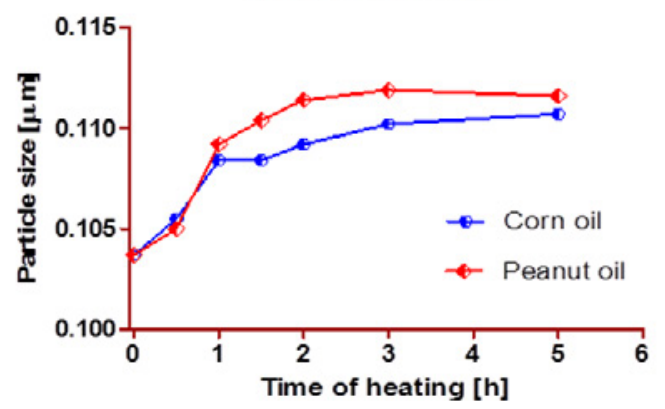

FIgURE 3. Variation of Particle size with time of heating to $190^{\circ} \mathrm{C}$ for corn and peanut oil using (a) PY model (b) SPT and (c) MCSL model by considering the average value of ultrasound data as the input with $n=1$. 
et al., 1959; Ravi et al., 2008). Fatty acid molecules in glycerol get distributed in oil depending on the change in the chemical potential $(\mu / \mathrm{kT})$, and also in inter-particle potential. Tables 3 and 4 elucidate the discrepancy of chemical potential (CP) with heating time. It can be observed that $\mathrm{CP}$ increases till 1 hour heated sample as more $\mathrm{RCOO}$ - and $\mathrm{H}+$ ions are formed by oxidation reaction. When the oil is further exposed to repetitive cycles of heating, Peroxides RCOO- undergo a hydrolysis chemical reaction with glycerol to form monomer, dimer, trimer, etc. Hence the CP value decreases for the sample S7 due to the energy released in the formation of polymers. Using the PY model, the CP value of corn oil is observed to increase by $35.2 \%$ compared to peanut oil as it has a smaller quantity of saturated fatty acids and also highly potent antioxidants. Moreover, peanut oil has a fractional amount of C22 long-chain fatty acid. In the SPT model, the CP value for corn oil is $19 \%$ greater than peanut oil, whereas it is greater than $12 \%$ using the MCSL model. By comparing the computed $\mathrm{CP}$ value for the three models $\mathrm{PY}>\mathrm{SPT}>\mathrm{MCSL}$ the interatomic distribution in molecules with the time of heating can be explained.

Corn oil has comparatively greater stability and can withstand even more heating cycles as more external energy is needed to alter the chemical species in oil samples (chemically inert) and this is justified by the observed
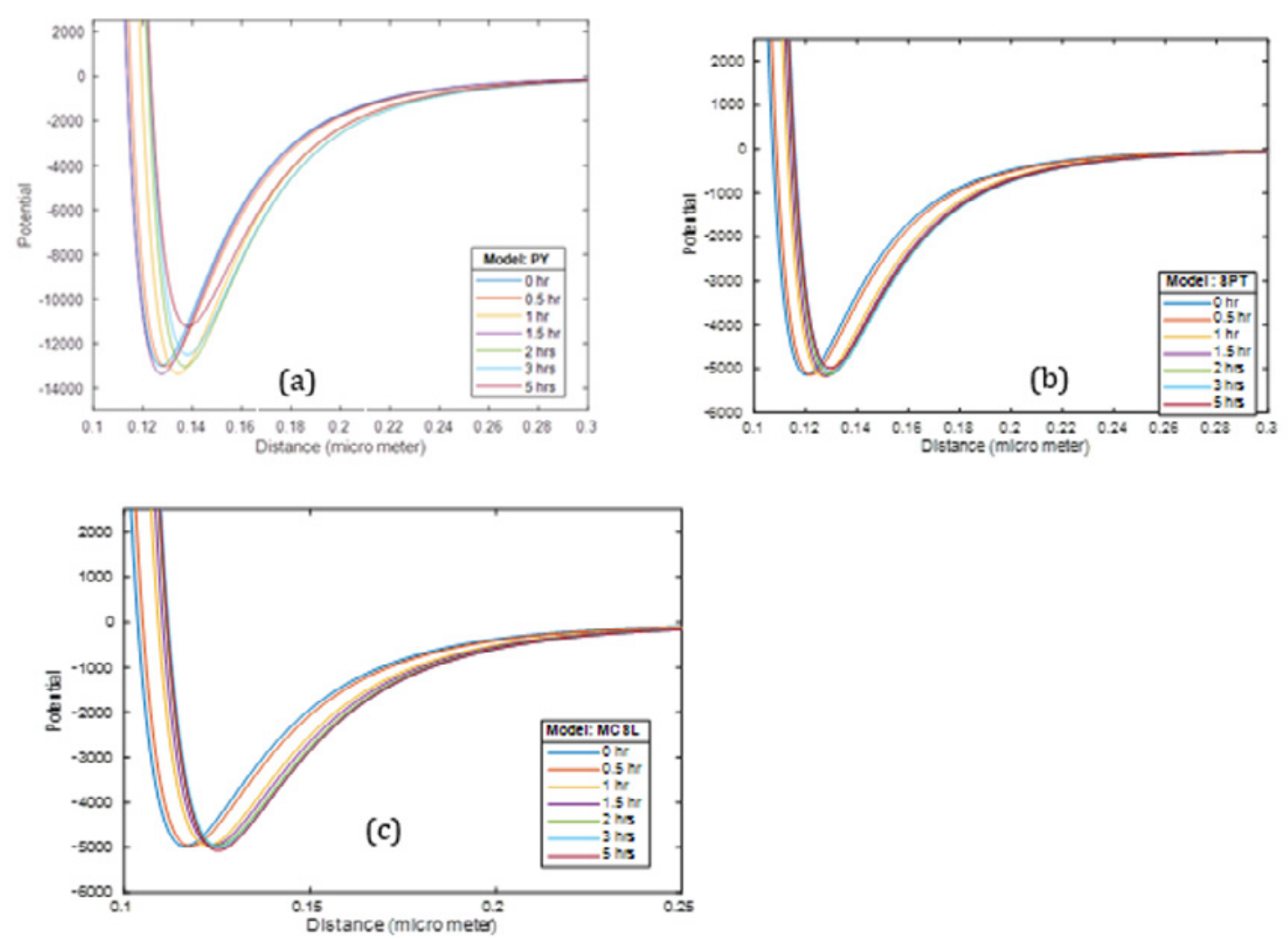

FIgURE 4. L-J potential plot for peanut oil at different duration of heating time to $190^{\circ} \mathrm{C}$ using (a) PY model (b) SPT model (c) MCSL model with $n=1$. The duration of heating has been given as inset. The interaction potential changes with heating duration. 
from Tables 3 and 4, inter-particle potential L-J has been plotted and is shown in Figures 4 and 5 for corn and peanut oil. Figure 4 (a) presents the way in which the minimum potential energy of corn oil upsurge by the increases in inter-particle distance by $8.57 \%$ from 0 to 5 hours of heating using the PY hard-sphere model; whereas using the SPT model it increases by $13 \%$. From the graph, the closest possible distance $\mathrm{g}(\mathrm{r})$ (also termed radial distribution function) has been observed around 0.12. A shift in internal energy is observed from the comparison plot which varies with heating cycles. The plot is drawn for 1.5-hour heating and 5 hours of heating and a shift was observed in peanut samples due to the breaking of bonds. Changes in the dynamic properties with the propagation of an ultrasonic wave through the sample is due to the presence of irregular long-chain molecules that produce more pressure than short-chain fatty acid in the oil. Using the MCSL hard-sphere model, the lowest potential energy increases by $13.6 \%$ from 0.5 to 5 hours of heating with respect to the interatomic distance of atoms in corn oil. Results obtained from the MCSL model almost match the SPT results.

Figure 5 (a) illustrates the variation in potential with a $7.4 \%$ increase in the interatomic distance using the PY model in peanut oil. The variation in interatomic distance is $7.69 \%$ using SPT and $16.4 \%$ using the MCSL model. The results calculated using the PY and SPT models are almost the same; whereas the MCSL model estimation is nearly twice the predicted PY and SPT. Hence to conclude, using this demonstrated L-J potential one can estimate the distribution of molecules using the hard-sphere models with an increase in heating duration.

Particle fraction, particle size, chemical potential, and L-J potential were computed using MATLAB. The low packing fraction and particle size of peanut oil were exemplified and compared to corn oil as it possesses a large amount of saturated and monounsaturated fatty acids.

Simulated output exhibits the distribution of molecules in oil samples that are made up of long and short flexible fatty acid chains and also additive mixtures of glycerol, antioxidants, etc., and agrees with existing data and the standard equations of state. The three hard-sphere models help to understand the chemical reaction taking place in oil exposed to different heating cycles. The CP and L-J potential also states remarkable computational advantages in the simulation to understand the different chemical composition in the oil and their potential variations after each cycle of heating (Stanciu, 2019).

\section{CONCLUSION}

Variations in the ultrasonic velocity, density, and viscosity of peanut oil and corn oil samples exposed to different
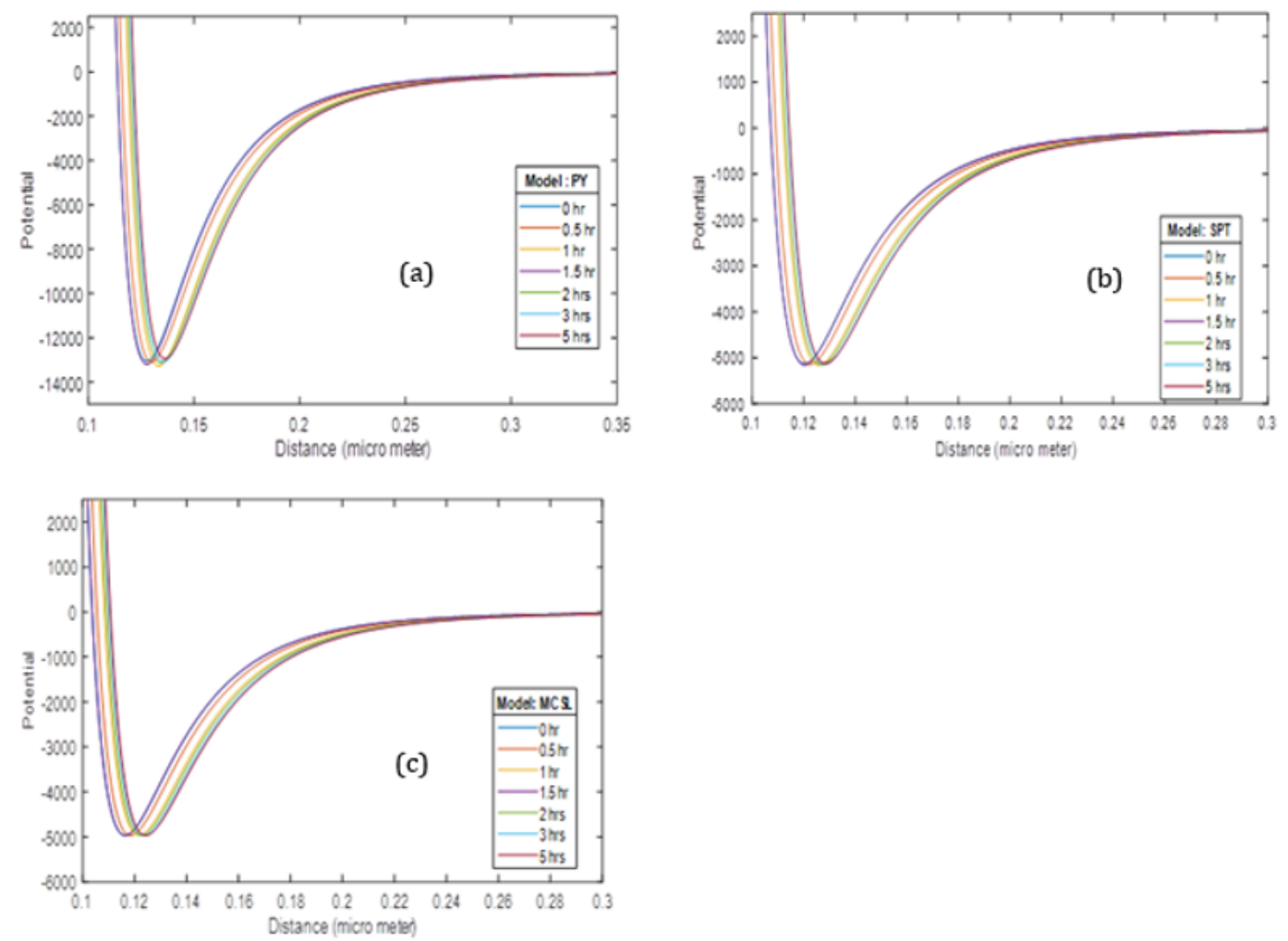

FIGURE 5. L-J potential plot for peanut oil at different duration of heating time to $190^{\circ} \mathrm{C}$ using (a) PY model (b) SPT model (c) MCSL model with $n=1$. The duration of heating has been given as inset. The interaction potential changes with heating duration. 
heating cycles at $190{ }^{\circ} \mathrm{C}$ were studied. From the physical parameter variations, it is observed that compared to peanut oil, corn oil can be used in more frying cycles. In corn oil, inter-particle potential, chemical potential, and particle diameter exhibit higher oxidative stability than peanut oil. Molecular simulation (PY, SPT, MCSL) can be used to study the distribution of molecules in oil upon degradation and also the forces existing between the atoms or molecules. From a practical perspective, these theories can be used to estimate the equation of state for long and short-chain polymer molecules in oil. The L-J potential graph shows the maximum closest distance between particles from the depth of the graph that is plotted, which exhibits the required external energy to break the bonding in long-chain fatty acids. L-J has been drawn based on the fact that SPT and MCSL matches well than PY, which illustrates that corn oil can be used for more heating cycles compared to peanut oil with less degradation. From the measured physical properties and using the computed particle distance against the potential of corn and peanut oil, the quality of the oil can be decoded.

\section{Acknowledgement}

Authors are grateful to the Chancellor, SASTRA Deemed University for allowing us to carry out the experimental study in the University lab and also for his constant support and encouragement.

\section{REFERENCES}

Benedito J, Garcia-Perez JU, Dobarganes MC, Mulet A. 2007. Rapid evaluation of frying oil degradation using ultrasonic technology. Food Res. Int. 40, 406-414. https://doi.org/10.1016/j.foodres.2006.10.017

Benedito J, Mulet A, Velasco J, Dobarganes MC. 2002. Ultrasonic Assessment of oil quality during frying. J. Agri. Food Chem. 50, 4531-4536. https://doi. org/10.1021/jf020230s

Brkić Bubola K, Klisović D, Lukić I, Novoselić A. 2020. Vegetable species significantly affects the phenolic composition and oxidative stability of extra virgin olive oil used for roasting. LWT 129, 109628. https:// doi.org/10.1016/j.1wt.2020.109628

David William G. 2008. The Chemistry of essential oil, 2nd ed, Micelle press, UK, 248-316.

Fasina OO, Hallman H, Craig Schmidt M, Clements C. 2006. Predicting temperature - dependence viscosity of vegetable oils from fatty acid composition. $J$. Am. Oil Chem. Soc. 83 (10), 899-903. https://doi. org/10.1007/s11746-006-504-8

Hemmat Esfe M, Sadati Tilebon SM. 2020. Statistical and artificial based optimization on thermo-physical properties of an oil based hybrid nanofluid using NSGA-II and RSM. Physica A. 537, 122126. https://doi. org/10.1016/j.physa.2019.122126
Heying M, Corti DS. 2004. Scaled Particle Theory Revisited: New conditions and improved predictions of the properties of the hard sphere fluid. J. Phy. Chem. B. 108, 19756 -19768. https://doi.org/10.1021/jp040398b Izbaim D, Faiz BA, Mouden A, Taifi N, Aboudaoud I. 2010. Evaluation of the performance of the frying oils using an ultrasonic technique. Grasas Aceites 61 (2), 151-156. https://doi.org/10.3989/gya.087709

Jacobson B, Heedman PA. 1953. Intermolecular Free Lengths in the Liquid State. Acta Chem. Scand. 7, 705712. https://doi.org/10.3891/acta.chem.scand.07-0705.

Kiełczynski P, Szalewski M, Balcerzak A, Wieja K, Malanowski A, Kościesza R, Tarakowski R, Rostocki AJ, Siegoczynski RM. 2014. Determination of physicochemical properties of diacylglycerol oil at high pressure by means of ultrasonic methods. Ultrasonics 54 (8), 2134 - 40. https://doi.org/10.1016/j.ultras.2014.06.013

Lebowitz JL. 1964. Exact Solution of Generalized Percus-Yevick Equation for a Mixture of Hard Spheres. Phy. Rev. 113, A895 - A899. https://doi.org/10.1103/ PhysRev.133.A895

Lennard-Jones JE. 1924. On the Determination of Molecular Fields. - II. From the Equation of State of a Gas. Proc. Royal Society London A. 106 (738), 463-477. https://doi.org/10.1098/rspa.1924.0082

Mandell MJ, Reiss H. 1975. Scaled Particle Theory: Solution to the Complete Set of Scaled Particle Theory Conditions: Applications to Surface Structure and Dilute Mixtures. J. Stat. Phys. 13 (2), 113 - 128. https:// doi.org/10.1007/BF01221372

Mansoori GA, Carnahan NF, Starling KE, Leland TW. 1971. Equilibrium Thermodynamic Properties of the Mixture of Hard Spheres. J. Chem. Phy. 54 (4), 15231525. https://doi.org/10.1063/1.1675048

McClements JD, Gunasekaran S. 1997. Ultrasonic Characterization of Foods and Drinks: Principles, Methods, and Applications. Crit. Rev. Food Sc. Nutrit. 37 (1), 1-46. https://doi.org/10.1080/10408399709527766

Pandey JD, Kumar V, Saxena MC. 1979. Evaluation of Jacobson's Constant and Intermolecular Free-Length as a Function of Pressure and Temperature for Cryogenic Liquids. Ultrasonics 17 (4), 153-158. https:// doi.org/10.1016/0041-624X(79)90032-5

Percus JK, Yevick GJ. 1958. Analysis of Classical Statistical Mechanics by Means of Collective Coordinates. Phys. Rev. 110 (1), 1-13. https://doi.org/10.1103/PhysRev.110.1

Ravi S, Amoros J, Arockia Jayalatha K. 2008. Effective method of characterizing specific liquid Fluorocarbon interactions using ultrasound. J. Phys. Chem. B. 112, 6420-6425. https://doi.org/10.1021/jp800812c

Reidoon Shahidi. 2005. Bailey's Industrial oil and Fat Products, 6th ed, Wiley- Inter science Publication, vol 2. chapter 12 , New york. 
Reiss H, Frisch HL, Lebowitz JL. 1959. Statistical Mechanics of Rigid Spheres. J. Chem. Phys. 31 (2), 369380. https://doi.org/10.1063/1.1730361

Rodenbush CM, Hsieh FH, Viswanatha DS. 1999. Density and Viscosity of Vegetable Oils. J. Am. Oil Chem. Soc. 76 (12), 1415-1419. https://doi.org/10.1007/ s11746-999-0177-1

Rubalya Valantina S, Phebee Angeline DR, Uma S, Jeya Prakash BG. 2017. Estimation of Dielectric Constant of Oil Solution in the Quality Analysis of Heated Vegetable Oil. J. Mol. Liq. 238, 136-144. https://doi. org/10.1016/j.molliq.2017.04.107

Rubalya Valantina S, Susan D, Bavasri S, Priyadarshini V, Ramya Saraswathi R, Suriya M. 2016. Experimental investigation of electro-rheological properties of modeled vegetable oils. J. Food Sci. Tech. 53 (2), 13281337. https://doi.org/10.1007/s13197-015-2050-6

Rubalya Valantina S, Chandiramouli R, Neelamegam P. 2013. Detection of adulteration in olive oil using rheological and ultrasonic parameters. Inter. Food Res. J. 20 (6), 3197-3202.

Sakai T, Hirano F. 1985. Effect of molecular weight distribution of mineral oils on their boiling heat transfer behaviour. Wear 104, 259-281. https://doi. org/10.1016/0043-1648(85)90052-3

Sanaeifar A, Jafari A. 2019. Determination of the oxidative stability of olive oil using an integrated system based on dielectric spectroscopy and computer vision, Inform. Process. Agric. 6, 20-25. https://doi. org/10.1016/j.inpa.2018.08.008

Sankarappa T, Prashant Kumar M, Ahmad A. 2005. Ultrasound Velocity and Density Studies in Some Refined and Unrefined Edible Oils. Phy. Chem. Liq. 43 (6), $507-$ 514. https://doi.org/10.1080/00319100500192889
Schössler K, Jäger H, Knorr D. 2012. Novel contact ultrasound system for the accelerated freeze-drying of vegetables. Innovative Food Sci. Emer. Tech. 16, 113-120. https://doi.org/10.1016/j.ifset.2012.05.010

Stanciu I. 2019. A new mathematical model for the viscosity of vegetable oils based on freely sliding molecules. Grasas Aceites 70 (3), e318. https://doi.org/10.3989/ gya.0824182

Thiele E. 1963. Equation of state for hard spheres. J. Chem. Phy. 39 (2), 474. https://doi.org/10.1063/1.1734272

Valdes AF, Garcia AB. 2006. A study of the evolution of the physicochemical and structural characteristics of olive and sunflower oils after heating at frying temperaturas. Food Chem. 98, 214-219. https://doi. org/10.1016/j.foodchem.2005.05.061

Wen P, Tie W, Wang L, Lee MH, Li XD. 2009. Ultrasonic synthesis of 4,4'-dihydroxychalcone and its photochemical properties. Mat. Chem. Phy. 117, 1-3. https:// doi.org/10.1016/j.matchemphys.2009.02.055

Wertheim MS. 1963. Exact Solution of the Percus-Yevick Integral Equation for Hard Spheres. Phys. Rev. Let. 10 (8), 321-323. https://doi.org/10.1103/PhysRevLett.10.321

Yarnell JL, Katz MJ, Wenzel RG, Koenig SH. 1973. Structure Factor and Radial Distribution Function for Liquid Argon at $85 \hat{\mathrm{A}}^{\circ} \mathrm{K}$. Phys. Rev. A. 7 (6), 21302144. https://doi.org/10.1103/PhysRevA.7.2130

Yu YX, Wu J. 2002. Structures of Hard-Sphere Fluids from a Modified Fundamental-Measure Theory. J. Chem. Phys. 117 (22), 10156-10164. https://doi.org/10.1063/1.1520530

Zhang L, Zhou C, Wang B, Yagoub AEA, Ma H, Zhang X, Wu M. 2016. Study of ultrasonic cavitation during extraction of the peanut oil at varying frequencies. Ultra. Sono. 37, 106 - 113. https://doi.org/10.1016/j. ultsonch.2016.12.034 